\title{
Atividades de Ensino no Moodle: Implicações da Fluência Tecnológica Digital do Professor
}

\author{
Daniele da Rocha Schneider - UFRGS - dani.qmc@gmail.com \\ Sérgio Roberto Kieling Franco - UFRGS - sergio.franco@ufrgs.br \\ Carlos Eduardo dos Santos Sabrito - UFRGS - csabrito@hotmail.com
}

\begin{abstract}
Resumo: O presente trabalho integra uma pesquisa de doutorado em andamento e objetiva analisar a fluência tecnológica digital do professor na elaboração e implementação de atividades de ensino no Moodle. A pesquisa constituiu-se em um estudo de caso com abordagem quantitativa e qualitativa. Os dados foram coletados através de entrevistas com professores e análise de disciplinas em ambientes virtuais de sete cursos de graduação a distância da UAB/UFSM. A análise amparou-se nos princípios da FTD: habilidades contemporâneas, conceitos fundamentais e capacidades intelectuais. Como resultado parcial foi possível verificar que a restrita diversidade de atividades de ensino implementadas nas disciplinas possui relação direta com a fluência tecnológica digital do professor.
\end{abstract}

Palavras-Chave: fluência tecnológica digital, atividades de ensino, professor

\section{Teaching activities in Moodle: implications of Digital Technological Fluency of Professor}

\begin{abstract}
This paper integrates a doctoral research in progress and aims to analyze the teacher's Digital Technological Fluency (DTF) in elaboration and implementation of teaching activities in Moodle. The research consisted in a case study with quantitative and qualitative approach. The data were collected through interviews with teachers and analysis of subjects in virtual environments of seven undergraduate distance courses of UAB/UFSM. The analysis was based on the principles of DTF: contemporary skills, fundamental concepts and intellectual capacities. As a partial result IT was possible to verify that the restricted range of teaching activities implemented in the disciplines has direct relation with digital technology fluency.
\end{abstract}

Keywords: digital technological fluency, educational activities, teacher

\section{Introdução}

A tecnologia tem se inserido nos contextos educativos de forma acelerada, possibilitando novas formas de produzir e socializar conhecimentos e informações. Diante desse cenário, o uso fluente das tecnologias digitais, na Educação a Distância (EAD), se constitui um desafio contemporâneo.

Essa nova conjuntura requer um professor capaz de adequar o planejamento e organização de qualquer proposta pedagógica às novas realidades do contexto educacional (LIBÂNEO, 2003). Para Macedo et. al. (2011, p. 9) “compreender a própria perspectiva epistemológica e aliá-la aos recursos tecnológicos pode favorecer melhores condições para administrar novos espaços e tempos de aprendizagem, potencializar as relações, as vivências e a multiplicidade de linguagens”. 
O professor “deve aprender a dominar e a valorizar não só um instrumento, ou um novo sistema de representação do conhecimento, mas uma nova cultura da aprendizagem” (MAURI; ONRUBIA, 2010, p.118). Nesse sentido Demo (1998, p.13), destaca que "quanto mais diversas forem as situações, quanto mais crítica seja a exploração dos recursos tecnológicos, mais enriquecedora será a aprendizagem”.

O professor que conhece e desenvolve habilidades em relação às tecnologias digitais tem possibilidade de criar, modificar, explorar e adaptar interativamente atividades de ensino, compartilhando novos conceitos, funções, programas e ideias.

Nessa perspectiva, discute-se nesse trabalho a fluência tecnológica digital de professores nas atividades de ensino no Moodle. Inicialmente destaca-se as escolhas teórico-conceituais problematizando o conceito de Fluência Tecnológica Digital (FTD) e Teoria da Atividade (TA). Num segundo momento apresenta-se os procedimentos metodológicos e os resultados da investigação.

\section{Fluência Tecnológica Digital}

A EAD traz novas configurações a prática docente por meio da tecnologia, requerendo metodologia própria e adequação pedagógica do conteúdo. Essa adequação metodológica e pedagógica diante da tecnologia, que está em constante mudança, pode ser potencializada pelo desenvolvimento de FTD.

A FTD (Figura 1) é uma competência que envolve reformular conhecimentos, expressar-se criativa e apropriadamente, produzindo e gerando informação.” (KAFAI et al, 1999, p.8). Potencializa a criação e reformulação de conteúdos digitais com múltiplas linguagens e mídias, atendendo a complexidade da prática pedagógica.

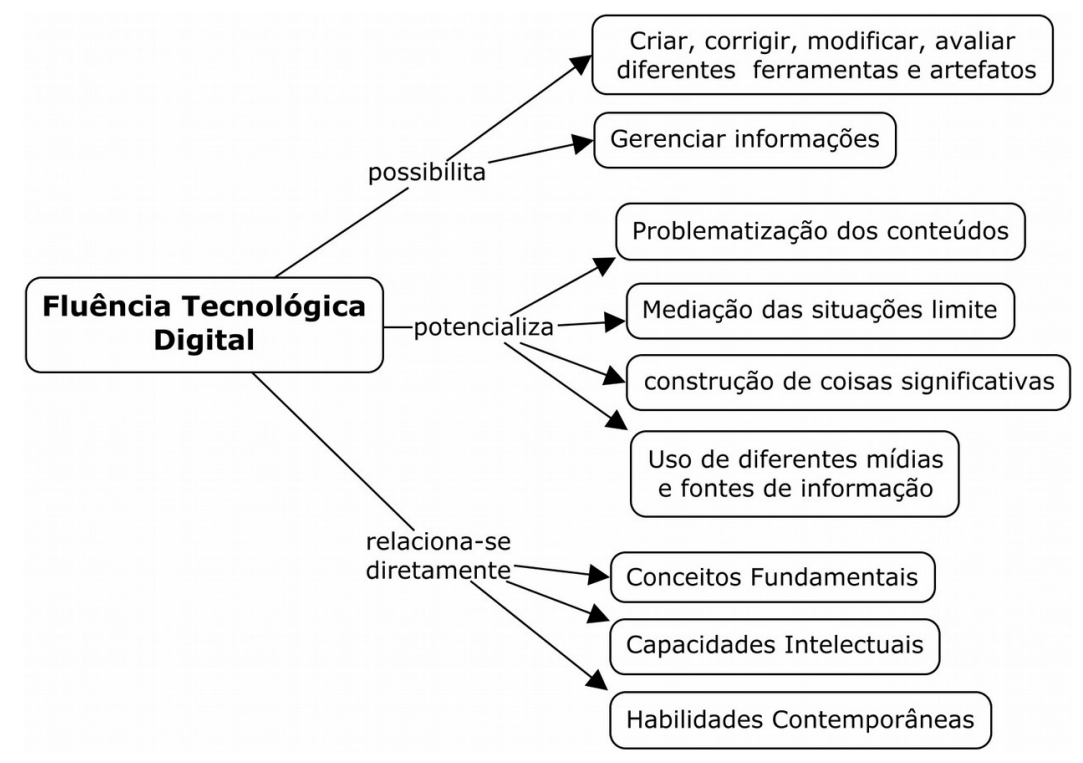

Figura 1 - Fluência Tecnológica Digital Fonte - Elaborado pelos autores

A FTD relaciona-se ao conhecimento das habilidades contemporâneas, conceitos fundamentais e capacidades intelectuais do professor (TAROUCO, 2013).

Habilidades contemporâneas implicam a capacidade de usar os aplicativos de computador atualmente disponíveis. No mercado de 


\begin{abstract}
trabalho atual, essas competências são um componente essencial da capacitação para o mercado de trabalho e fornecem uma base de experiência prática sobre a qual novas competências poderão ser construídas.

Conceitos fundamentais consistem nos princípios básicos sobre computadores, redes e informações que constituem a base da tecnologia. Tais conceitos explicam a tecnologia, motivação e possibilidade de seu uso, bem como suas limitações.

Capacidade intelectuais implicam as habilidades para aplicar a tecnologia da informação em situações complexas de forma continuada, manipulando os recursos tecnológicos para resolver problemas por mais inesperados que sejam. Isso demanda o uso de pensamento abstrato sobre a informação e sua manipulação. (TAROUCO, 2013, p. 288 - 289)
\end{abstract}

A FTD dos professores está diretamente relacionado à tecnologia, a pedagogia, ao conteúdo curricular, ao contexto envolvido que implica saber utilizar, compreender, criar e compartilhar coisas novas com as tecnologias digitais. É dessa forma que se potencializa interação e interatividade no processo ensino-aprendizagem no Moodle. Desse modo, quanto mais elevados os níveis de FTD do professor, maiores os avanços em termos do desenvolvimento da prática emancipatória nas atividades de ensino a distância.

Para Demo, a FTD

Vai muito além de saber usar na posição de consumidor de programas e informações. Atinge os patamares da criação de informação, busca semântica de informação, formação de autoria. Assim, podemos entender fluência tecnológica como habilidade minimalista de digitar texto, navegar na internet, conhecer comandos repetitivos, mas igualmente como exigência rebuscada de dar conta de empreitadas não-lineares interpretativas, nas quais a postura é de sujeito participativo/reconstrutivo (DEMO, 2008, p. 7).

Num ambiente onde a educação e a tecnologia se interconectam, o professor com FTD tem capacidade de adaptar metodologias de ensino, exercitando suas possibilidades didático-pedagógicas pois, [...] o que faz com que um processo de ensino e de aprendizagem seja eficiente não é a opção tecnológica, mas sim a proposta epistemológica-didático-pedagógica que suporta o uso de determinada tecnologia. (SCHLEMMER; BACKES, 2008, p. 530).

Belloni (2001, p. 53), destaca que a relação entre educação e tecnologia implica em "que o uso de uma 'tecnologia' (no sentido de um artefato técnico), em situação de ensino e aprendizagem, deve estar acompanhado de uma reflexão sobre a 'tecnologia' (no sentido do conhecimento embutido no artefato e em seu contexto de produção e utilização)". Isso implica que maiores níveis de FTD potencializam as problematizações dos conteúdos de ensino e aprendizagem. Por isso, defende-se que a FTD do professor é condição para o planejamento e implementação das atividades de ensino no Moodle.

\title{
Teoria da Atividade
}

A Teoria da Atividade (TA), embasada nos pressupostos básicos do pensamento Vygotskiano e difundida por Lúria, Leontiev, Davidov entre outros seguidores, fundamenta-se na importância do ensino na formação humana, em termos de desenvolvimento psíquico e intelectual, de apropriação e inserção da/na cultura social vigente e da construção social da aprendizagem por meio de atividades. 
A TA “é uma estrutura filosófica e interdisciplinar para estudar as diferentes formas de práticas humanas como processos de desenvolvimento, com os níveis individual e social ligados ao mesmo tempo"(KUUTT,, 1996, p. 25). Possibilita a compreensão da atividade humana e a educação inserida como uma atividade dos homens para produção de saberes num processo construtivo e social.

Na TA o conhecimento é desenvolvido na mediação das ferramentas usadas no processo de ensino e aprendizagem. Para Libâneo:

A teoria da atividade presta-se a muitas finalidades, mas especialmente pode auxiliar nas formas de desenvolvimento do pensamento teórico (valendo para os alunos, mas também para os professores); na compreensão da estrutura da atividade docente; na explicitação dos procedimentos e definição de ações e tarefas de aprendizagem para aumentar a eficácia das aprendizagens; na proposição de métodos e procedimentos de estudo e análise das práticas, em especial, os contextos socioculturais da atividade, para promover a transformação de espaços institucionais (...).(LIBÂNEO, 2005, p.16)

Para

Leontiev

$(1998$,

p.

68),

atividades são “(...) aqueles processos que, realizando as relações do homem com o mundo, satisfazem uma necessidade especial correspondente a ele. Nesse mesmo sentido, Davidov (1988, p. 11) afirma que: “a atividade do homem tem uma estrutura complexa; seus componentes são as necessidades, os motivos, as finalidades, as tarefas, as ações e as operações que se encontram em permanentes inter-relações e transformações".

Assim, as AE são "um conjunto de ações (finalidade) e operações (práticas e intelectuais) que levam à formação do pensamento teórico, assentado na reflexão, análise e planejamento mental” (ALBERTI; FRANCO, 2010, p.06). Apresentam um conteúdo (no caso, o curricular) e uma estrutura especial exigindo planejamento com finalidades a serem alcançadas nas etapas do processo de ensino (DAVIDOV, 1988).

Nesse viés, a AE sempre prescindem de ações planejadas, de metas conscientes à serem alcançadas para gerar aquisição de conhecimento teórico (ALBERTI, 2011). Para tudo isso, de acordo com a teoria proposta por Davidov (1988), o professor precisa planejar, monitorar e avaliar as atividades de estudo. No caso dos ambientes informatizados isso somente se torna possível mediante desenvolvimento de habilidades contemporâneas, conceitos fundamentais e capacidades intelectuais da fluência tecnológica.

\section{Estratégia Metodológica}

Esse trabalho, como um recorte temático de uma pesquisa de doutorado em andamento, foi realizado em cursos de graduação a distância, oferecido pela Universidade Federal de Santa Maria (UFSM) no âmbito do programa Universidade Aberta do Brasil (UAB). A coleta dos dados ocorreu entre 2015 e 2017 através de análise de documentos oficiais dos cursos, observação direta dos ambientes virtuais e entrevistas com professores.

As observações foram realizadas em ambientes virtuais de 33 disciplinas disponibilizadas no Moodle, distribuídas em 7 cursos de graduação ofertados no segundo semestre de 2014. Do total de 33 professores relacionados as disciplinas 
observadas, 17 realizaram a entrevista.

Os dados foram analisados amparando-se nos princípios da FTD: habilidades contemporâneas, conceitos fundamentais e capacidades intelectuais. Para esse trabalho, destacamos duas questões da entrevista diretamente relacionada a FTD na ferramenta atividade do Moodle, as quais serão analisadas no tópico seguinte.

\section{Análise dos Dados}

Realizamos a análise apresentando os dados coletados a partir de entrevistas com professores e observação no ambiente virtual Moodle. A amostra envolveu 33 disciplinas ofertadas no segundo semestre de 2014, nos cursos de Graduação a distância da UAB/UFSM.

O Moodle possibilita o desenvolvimento de atividades de ensino individuais e colaborativas. Entre essas atividades destacam-se algumas como fórum, tarefa, wiki, questionário, enquete, lição, glossário, escolha, diário, base de dados, Hot Potatoes, pesquisa entre outras. Em relação as 33 disciplinas analisadas, contabilizou-se um total de 223 atividades de ensino implementadas no período de um semestre. Essas 223 atividades ficaram restritas a fóruns (75), tarefas (87), questionários (47), Hot Potatoes (08), wiki (2) e lição (4). Isso caracteriza a utilização de $32 \%$ das diferentes possibilidades de atividades de ensino que o Moodle disponibiliza.

Considerando que o planejamento e implementação de AE assume importância significativa no desenho pedagógico, à medida que deve possibilitar o desenvolvimento psíquico e intelectual do estudante, a utilização restrita de determinados tipos de AE pode ser indicativo de baixa FTD. Para confirmar ou não essa hipótese, realizou-se entrevista com 17 professores (52\%) que atuaram nas disciplinas analisadas.

Quando questionados se possuíam FTD nas atividades que destacavam utilizar (Tabela 1), menos de $50 \%$ dos respondentes demonstraram certeza dessa fluência. Fluência no sentido de conhecer e apropriar-se das ferramentas educacionais, seus princípios e aplicabilidade em diferentes situações. Criar, corrigir, modificar interativamente diferentes ferramentas e artefatos, compartilhando novos conceitos, funções, programas e ideias (KAFAI et al, 1999).

Tabela 1- Fluência tecnológica digital nas atividades de ensino

Fonte - Elaborado pelos autores

\begin{tabular}{|c|c|}
\hline Professor & Quais atividades do Moodle você utiliza? Acredita possuir FTD nas mesmas? \\
\hline 1 & $\begin{array}{l}\text { Fórum, tarefa, questionário, diário, enquete. "Eu me considero bem ambientada, eu tive } \\
\text { sempre um perfil de tutora muito próximo, mediador, então hoje quando eu opto pelas } \\
\text { ferramentas eu acabo fazendo a parte técnica de colocar no Moodle a atividade e depois de } \\
\text { estar mediando isso". }\end{array}$ \\
\hline 2 & $\begin{array}{l}\text { Fórum, questionário, tarefa, wiki ( “a wiki eu nunca tive sucesso em usar, eu acho que nunca } \\
\text { soube propor uma atividade legal”). "Com relação ao Moodle sim, eu consigo ter um bom } \\
\text { relacionamento, eu faço o que preciso fazer".[...] eu vou clicando e tentando descobrir, eu } \\
\text { não tenho medo". }\end{array}$ \\
\hline 3 & Fóruns. “Eu aprendo informática sempre mexendo” \\
\hline 4 & $\begin{array}{l}\text { Fórum e questionário. "Usar os recursos tecnológicos disponíveis eu não tenho dificuldade } \\
\text { nenhuma, como usuário eu não tenho dificuldade”. }\end{array}$ \\
\hline 5 & Usava quase todos. "Sim, sim, tenho domínio”. \\
\hline 6 & Fórum e tarefa. "Essa questão toda digital, as vezes eu tenho um certo receio, que não vai \\
\hline
\end{tabular}




\begin{tabular}{|c|l|}
\hline & funcionar, que eles não vão entender”. \\
\hline 7 & $\begin{array}{l}\text { Chat, Fórum, glossário, Tarefa. “Te diria que sim, me colocaria como alguém que sabe } \\
\text { utilizar bem essas ferramentas e utilizá-las pedagogicamente de maneira apropriada”. }\end{array}$ \\
\hline 8 & $\begin{array}{l}\text { Tarefa, fóruns. “Sim. Eu brincava no Moodle, eu deixava invisível e fazia os exercícios aí } \\
\text { depois eu mudava meu papel para estudante para ver como aparecia [...] ficava mexendo nas } \\
\text { atividades e enviando para ver como aparece e o que acontece”. }\end{array}$ \\
\hline 9 & $\begin{array}{l}\text { Fórum. “Tenho sim, custei pra aprender mas consegui”. [...] tenho uma tutora maravilhosa, } \\
\text { aí eu digo explica pra mim [...] aí a gente senta junto e ela fica me explicando”. }\end{array}$ \\
\hline 10 & $\begin{array}{l}\text { Enquete, questionário, glossário, diário, wiki. “ Sim, eu trabalho desde a graduação com } \\
\text { isso. Isso é algo tranquilo para mim”. }\end{array}$ \\
\hline 11 & Tarefa, fórum. “Sim, procuro me reinventar sempre”. \\
\hline 12 & Questionário.”Eu uso bem o Moodle, uso o Moodle intensivamente”. \\
\hline 13 & Tarefa. “Me considero fluente no que preciso”. \\
\hline 14 & Fórum, tarefa. “Eu acho, eu acho. Boa pergunta” \\
\hline 15 & $\begin{array}{l}\text { Tarefa, fórum. “Eu diria que sou parcialmente fluente, no seguinte sentido, estas atividades } \\
\text { que acabei utilizando mais, eu me sinto muito seguro para trabalhar, [...] mas não } \\
\text { necessariamente de explorar todas as atividades”. }\end{array}$ \\
\hline 16 & $\begin{array}{l}\text { Tarefa, fórum, wiki. "Não sei se eu posso me considerar uma pessoa fluente, acho que não. } \\
\text { Acho que eu consigo fazer um bom trabalho pensando num todo. }\end{array}$ \\
\hline & $\begin{array}{l}\text { Hot Potatoes, fórum. "Eu diria que um pouco, eu entendo um pouquinho de programação de } \\
\text { site, consigo fazer algumas coisas.[...] aprendi por conta, tudo por conta”. }\end{array}$ \\
\hline
\end{tabular}

Em relação ao tipo de AE, verifica-se conformidade com os dados observados no ambiente. Muitos professores justificaram a opção específica pelas atividades destacadas em função do perfil da disciplina, falta de tempo para explorar as demais opções, dificuldade tanto pessoal quanto dos alunos em implementar a atividade wiki. Destacaram positivamente o fórum como uma das poucas opções para promover interação e colaboração entre os estudantes.

Ao implementar uma AE, o professor precisa desenvolver flexibilidade e fluência da tecnologia, da pedagogia, do conteúdo e contexto envolvido, ou seja, qualquer ação que tenha implicações em novas posturas frente ao conhecimento conduz a uma renovação da prática pedagógica (PERRENOUD, 2000). Num segundo momento solicitou-se ao professores sugestão para melhorar a FTD a partir das suas necessidades e concepções (Tabela 2).

Tabela 2 - Opinião dos professores relacionadas à melhoria da fluência tecnológica digital Fonte - Elaborado pelos autores

\begin{tabular}{|c|l|}
\hline Professor & \multicolumn{1}{|c|}{ Sugestões para melhoria da Fluência Tecnológica Digital } \\
\hline 1 & $\begin{array}{l}\text { "Para as ferramentas novas, um passo a passo para além das formações, um tutorial porque } \\
\text { é difícil além de tentar fazer temos que testar porque o aluno pode ter dificuldade”. [...] } \\
\text { para além disso eu acho que a gente está muito apegado ainda a no fórum, tarefa e } \\
\text { questionário porque é o mais próximo que a gente tem da atividade presencial”. }\end{array}$ \\
\hline 2 & $\begin{array}{l}\text { “Como fazer o Moodle realmente um ambiente de aprendizagem a distância, [...] eu acho } \\
\text { que é uma coisa bem anterior que é formação, quando eu me formo professora. Então eu } \\
\text { acho que a fluência tecnológica se tu é uma pessoa que clica tu consegue. Um dia tu acaba } \\
\text { aprendendo. Mas e juntar o tecnológico com o pedagógico é mais difícil realmente. Eu acho } \\
\text { que falta uma preparação na formação”. }\end{array}$ \\
\hline
\end{tabular}




\begin{tabular}{|c|c|}
\hline 3 & $\begin{array}{l}\text { "É questão de metodologia. É algo processual, tu tem que estar sempre se atualizando. } \\
\text { Considerando as modalidades o que muda é a metodologia, aprendizado da informática x } \\
\text { aprendizado pela informática." }\end{array}$ \\
\hline 4 & $\begin{array}{l}\text { "Vai depender do professor, das concepções dele de aula e das concepções de aula a } \\
\text { distância. O Moodle é uma baita tecnologia em termos de informação, de TIC mas em } \\
\text { termos pedagógicos ele não tem inovação. Ele não tem uma velocidade pedagógica[...] tem } \\
\text { a inovação tecnológica”. }\end{array}$ \\
\hline 5 & 'Eu acho tranquilo. Pra mim tá bom.' \\
\hline 6 & $\begin{array}{l}\text { "Teria que fazer um curso aí é presencial, eu dou aula, aí não vai fechar horário, talvez algo } \\
\text { mais explicativo, mais passo a passo, um tutorial. [...] Se for vê as vezes tem, tem todo um } \\
\text { material enorme, não dá. Eu não tenho tempo para isso.” }\end{array}$ \\
\hline 7 & $\begin{array}{l}\text { "Muita gente reclama do Moodle sem conhecer o Moodle. Quando a gente conhece uma } \\
\text { ferramenta e entende que determinado aspecto daquela ferramenta ajuda a resolver um } \\
\text { problema da vida real, então a gente acaba sendo mais simpático a ferramenta. Eu penso } \\
\text { que grande parte da resistência pelo Moodle se dá pela falta de conhecimento a respeito } \\
\text { dele. Se a gente manuseia e conhece o recurso aprende a tirar dele o que a gente pode ou } \\
\text { precisa." }\end{array}$ \\
\hline 8 & $\begin{array}{l}\text { “Eu acho que capacitaç̃̃es são necessárias, não só explicar o que é o Moodle, mas como se } \\
\text { pensar o ensino a distância e que tipo de aluno é esse no ensino a distância e que professor é } \\
\text { esse.” }\end{array}$ \\
\hline 9 & $\begin{array}{l}\text { "Eu acho que o problema é eu, e não do sistema. O sistema tá tranquilo, eu que tenho que } \\
\text { saber, aprender a mexer. Tem professor que acha que ensino a distância é você pegar o } \\
\text { presencial e botar na internet, e não é. Aluno presencial é uma coisa, aluno a distância e } \\
\text { totalmente diferente. [...] essa diferença que a gente tem que trabalhar [...] é muito } \\
\text { complicado porque é outra linguagem, são outros valores e é outro modo de ver a relação } \\
\text { ensino e aprendizagem.” }\end{array}$ \\
\hline 10 & $\begin{array}{l}\text { "Os jovens hoje em dia não tem fluência, eles sabem manipular a ferramenta mas não sabe } \\
\text { o que a ferramenta pode possibilitar, os caminhos pedagógicos isso eu acho que através de } \\
\text { uma bela pesquisa e de estudo da ferramenta que tu quer trabalhar. [...] nessas descobertas } \\
\text { da tecnologia na área educacional a gente tá testando, nada definido, nada escrito que } \\
\text { realmente a tecnologia pode ou ela foi feita." }\end{array}$ \\
\hline 11 & $\begin{array}{l}\text { "Falta não só capacitação técnica, isso tem. Falta capacitação de como fazer oficina de } \\
\text { diálogo com o professor, como é que a gente pode usar, eu não diria motivacional, mas com } \\
\text { orientações, com recursos, com estratégias. [...] Uma capacitação mais de cunho } \\
\text { pedagógico do que técnico, o técnico é importante, porque nós temos que saber } \\
\text { operacionalizar, mas tem que focar no pedagógico, que aluno que eu quero formar[...]”. }\end{array}$ \\
\hline 12 & $\begin{array}{l}\text { "Não é questão de mudar para os professores terem mais fluência, é que as pessoas que nós } \\
\text { somos, elas não são para isso, precisa outras pessoas, precisamos deixar de ser o que somos } \\
\text { para tratar isso de outra forma, que é uma forma mais contemporânea, inverter e mudar } \\
\text { completamente nossas práticas e o modo de fazer”. }\end{array}$ \\
\hline 13 & $\begin{array}{l}\text { "Precisa mais momentos presenciais para manipular junto com quem sabe” Para isso falta o } \\
\text { tempo". }\end{array}$ \\
\hline 14 & $\begin{array}{l}\text { "Eu acho que é da curiosidade e também tem a ver com algo muito importante que é com o } \\
\text { que a gente quer, quem são essas pessoas que a gente quer formar. [...] fazer } \\
\text { interdisciplinar, a gente tem muita gavetinha." }\end{array}$ \\
\hline 15 & “Eu acho que deveria ser mais claro assim, de como fazer talvez.” \\
\hline 16 & $\begin{array}{l}\text { "Tempo, porque tendo tempo nós vamos poder explorar novos recursos, novas ferramentas, } \\
\text { outros softwares, e tendo esse tempo explorando com o conhecimento já adquirido nós já } \\
\text { conseguimos fazer um trabalho interessante. }\end{array}$ \\
\hline 17 & “O tempo." \\
\hline
\end{tabular}


A partir da análise dos dados sistematizados na tabela 2, observa-se alguns indicadores em relação a FTD destacados pelos professores: gestão do tempo, clareza pedagógica em relação a EAD, necessidade de capacitação mais de cunho pedagógico, conhecimento das possibilidades e potencialidades das $\mathrm{AE}$, questão metodológica, formação docente para atuação na EAD, necessidade de tutoriais específicos.

Observa-se um consenso entre alguns professores em relação a tríade formação do docente, os saberes docentes e a EaD. Há um reconhecimento das diferentes particularidades e necessidades de cada modalidade, fato que inviabiliza a simples transposição da prática pedagógica do presencial para o a distância, conforme destacado pela professora 1. A docência na EAD se configura (ou deveria se configurar) de maneira diferenciada, o que requer FTD em questões didático-metodológicas e tecnológicas, assim como domínio de conteúdos.

A preocupação em desenvolver FTD em relação a tríade, corrobora com Mishra \& Koehler (2006), na definição de Technological Pedagogical Content Knowledge (TPACK) como uma forma emergente de conhecimento que perpassa o conteúdo, pedagogia e tecnologia. Perpassa o conhecimento sobre os processos e práticas ou métodos de ensino e aprendizagem e sua abrangência em relação aos fins educativos, valores e objetivos. Através do TPACK o professor desenvolve a capacidade de saber usar as tecnologias, numa dada área curricular, a partir de uma estratégia pedagógica, num determinado contexto, promovendo a construção do conhecimento (COLL e MONEREO, 2010).

A docência na EAD é uma atividade complexa, não somente devido às características próprias da docência per se, mas também pela intrincada conjugação das ações dos diversos atores envolvidos neste empreendimento (RIBEIRO, et al. 2010, p. 85).

As opiniões destacadas pelos professores 3 e 4, problematizam o Moodle como inovação tecnológica na qual aprende-se a informática e não pela informática. Neste sentido Mill (2010), destaca que a incorporação isolada de tecnologias digitais no âmbito da educação não garante inovações pedagógicas. E ainda segundo o autor "refletir sobre inovações tecnológicas e sua relação direta com as inovações pedagógicas requer compreensão do contexto social e do estágio de desenvolvimento tecnológico da época dada. (MILL, 2010, p. 44).

Destaca-se a fala dos professores 7 ("Se a gente manuseia e conhece o recurso aprende a tirar dele o que a gente pode ou precisa.”), 9 (“Eu acho que o problema é eu”) e 14 ("Eu acho que é da curiosidade”) as quais remetem a si próprios a responsabilidade em relação ao desenvolvimento da FTD. Para Kruger (2006) a tecnologia permite agir sobre a situação (no nosso caso, a AE), e pensar sobre ela. Tecnologia entendida como um "conjunto de conhecimentos e princípios científicos que se aplicam ao planejamento, à construção e à utilização de um equipamento em um determinado tipo de atividade" (KENSKI, 2011, p. 24).

“Atingir um alto nível de fluência tecnológica permite um nível de conforto com o momento tecnológico atual e a habilidade de confrontar novos desenvolvimentos com certa desenvoltura"(AMIEL; AMARAL, 2013, p. 03) por isso os professores precisam ampliar a FTD nas AE no sentido da experimentação em relação as habilidades contemporâneas, conceitos fundamentais e capacidades intelectuais. 


\section{Considerações finais}

O objetivo dessa pesquisa é problematizar a FTD dos professores na AE. Considerando que a mesma se encontra em andamento, podemos inferir alguns resultados parciais em relação aos dados apresentados. Em relação a diversidade de AE que o Moodle disponibiliza verificou-se coerência entre os tipos de AE que foram visualizados no ambiente e destacados pelos professores na entrevista, ou seja, se apropriam apenas de $1 / 4$ das possibilidades. Fato esse que indica possíveis fragilidades em relação ao desenvolvimento de FTD.

Quando questionados a respeito de como a FTD dos professores poderia ser ampliada e potencializada considerando as próprias concepções em relação ao processo educacional nas diferentes modalidades, muitas respostas convergiram. Isso indica um possível caminho para implementação de formações continuadas que venham a suprir aspectos específicos da FTD.

Nesta perspectiva, faz-se necessário a problematização da implementação de AE diversificadas, que requerem novas concepções do fazer pedagógico diante das inovações possibilitadas pelo desenvolvimento tecnológico. Inovação que requer constante desenvolvimento da FTD em relação a seleção e implementação de AE e sua aplicabilidade em diferentes situações didáticas. Compreender essa relação é uma realidade necessária aos professores pois, as informações fluem com rapidez, requerendo clareza epistemológica e conceitual para proposição de práticas pedagógicas coerentes com a modalidade de ensino.

Portanto, a presente pesquisa, a partir de sistematização de indicadores pode contribuir com possíveis modelizações teórico-prática que possam ressignificar papeis face às novas demandas institucionais.

\section{Referências bibliográficas}

ALBERTI, T. F. FRANCO, S. R. K. Das Possibilidades da Formação Profissional a Distância: Um Estudo na Perspectiva da Teoria da Atividade. In: Encontro de Pesquisa em Educação da Região Sul (ANPED Sul) - Formação, Ética e Políticas: Qual Pesquisa? Qual Educação? Londrina: Anped, 2010. v. 1. p. 1-10.

BELLONI, M. L. Educação a distância. $5^{\circ}$ ed. Campinas, SP: Autores Associados, 2008.

DAVIDOV, V. La enseñanza escolar y el desarrollo psíquico. Prefácio. Moscu, Editorial Progresso, 1988.

DEMO, P. Habilidades do Século XXI, Boletim Técnico do SENAC, Rio de Janeiro, v. 34, $\mathrm{n}^{\circ}$ 02, maio/ago. 2008. p.389-404. Disponível em: http://www.senac.br/BTS/342/artigo-1.pdf. Acesso em: 02 abr. 2017.

KAFAI, Y. et al. Being Fluent with Information Technology, 1999. Disponível em: <http://www.nap.edu/catalog/6482.html\&gt>; Acesso em: 02 abr. 2017.

KENSKI, V. Educação e tecnologias: o novo ritmo da informação. 8. ed. Campinas, SP: Papirus, 2011.

KRÜGER, S. E. Educação musical apoiada pelas novas Tecnologias de Informação e 
Comunicação (TIC): pesquisas, práticas e formação docentes. Revista da Abem, Porto Alegre: Ano XIV n.14, p. 75-89, mar. 2006.

KUUTTI, K. Activity Theory as a Potential Framework for Human-Computer Interaction Research. In: NARDI, B. A. (ed) Context and Consciousness: Activity theory and human-computer interaction. Cambridge, Mars: MIT Press, p.17-44, 1996.

LEONTIEV, A. N. Os princípios psicológicos da brincadeira pré-escolar. In: VIGOTISKY et al., Linguagem, desenvolvimento e aprendizagem. São Paulo: Ícone: 1988.

LIBÂNEO, J. C. A didática e a aprendizagem do pensar e do aprender - a teoria histórico cultural da atividade e a contribuição de Vasíli Davídov. Revista Brasileira de Educação. Rio de Janeiro: $n^{\circ}$ 27, 2005.

MACEDO, A. L.; BEHAR, P. A.; REATEGUI, E. Rede de conceitos: tecnologia de mineração de texto para apoiar práticas pedagógicas no acompanhamento da escrita coletiva. In: Revista Brasileira de Informática na Educação, vol. 19, no 1, 2011.

MISHRA, P., \& KOEHLER, M. J. Technological pedagogical content knowledge: A framework for teacher knowledge. Teachers College Record, 108(6), 1017-1054, 2006.

MILL, D. Das inovações tecnológicas às inovações pedagógicas: considerações sobre o uso de tecnologias na Educação a Distância. In: MILL, D.; PIMENTEL, N. (Orgs.). Educação a Distância: desafios contemporâneos. São Carlos: EdUFSCar, p.43-57, 2010.

MAURI, T.; ONRUBIA, J. O professor em ambientes virtuais: perfil, condições e competências. In: COLL, C.; MONEREO, C. (Org.). Psicologia da educação virtual: aprender e ensinar com as tecnologias da informação e da comunicação. Porto Alegre: Artmed, 2010. p. 118-135.

OLIVEIRA, M. K. de. Vygotsky: aprendizado e desenvolvimento, um processo sócio-histórico. São Paulo, Scipione, 111 p. 1997.

PERRENOUD, P. Dez novas competências para ensinar: convite à viagem. Porto Alegre: Artmed, 2000.

RIBEIRO, L. R. de C.; OLIVEIRA, M. R. G. de; MILL, D. A interação tutor-aluno na Educação a Distância. In: MILL, D. R. S.; RIBEIRO, L. R. de C.; OLIVEIRA, M. R. G. de. (Orgs.). Polidocência na educação a distância. São Carlos: EdUFSCar, 2010.

SCHLEMMER, E.; BACKES, L.. Metaversos: novos espaços para construção do conhecimento. Revista Diálogo Educacional, Curitiba: PUCPR, v.8, n. 24, mai./ago. 2008. Disponível em: $\quad$ http://www2.pucpr.br/reol/index.php/DIALOGO? dd1=2038\&dd99=view. Acesso em: 02 abr. 2017.

TAROUCO, L. M. R. Um panorama da fluência digital na sociedade da informação. In: Competências em Educação a Distância. BEHAR, P. A. (org.). Porto Alegre: Penso, 2013. 